\title{
Impact of Childhood Psychosocial Stressors on Adolescence Period and Its Management: A Case Study of Conversion Disorder
}

\author{
Robina Mahmood, ${ }^{1}$ Afreen Komal, ${ }^{2}$ Aftab Asif, ${ }^{3}$ Kiran Jawaid $^{4}$
}

\begin{abstract}
Functional Neurological Symptom Disorder, previously called as Conversion disorder, is very common psychological disorder in eastern countries like Pakistan. This case study is describing how psychosocial factors produce stress and made a young girl dysfunctional in all aspect of life. The patient F.Z was 18 years old unmarried girl and educated up till intermediate. She was unemployed and last born among 6 siblings; 4 sisters and 2 brothers. She was brought to the psychiatry indoor ward with speech symptom; unable to speak (aphonia), sensory symptom; could not see (psychogenic blindness) and more over since last few months she had paralysis of lower limbs. Apart from those symptoms she reported poor appetite, remained sad and tearful. She was assessed thro-ugh both informal and formal psychological assessment.
\end{abstract}

\footnotetext{
${ }^{1}$ Senior Clinical Psychologist, Academic Department of Psychiatry and Behavioral Sciences, KEMU/ Mayo Hospital, Lahore

${ }^{2}$ Clinical Psychologist, Research Coordinator, Academic Department of Psychiatry and Behavioral Sciences, KEMU/ Mayo Hospital, Lahore

${ }^{3}$ Head of Academic Department of Psychiatry and Behavioral Sciences, KEMU/ Mayo Hospital, Lahore

${ }^{4}$ Trainee Psychologist, Academic Department of Psychiatry and Behavioral Sciences, KEMU/ Mayo Hospital, Lahore
}

Date of Submission: 30-12-2016

Date of Acceptance for Publication: 16-03-2017

Conflict of Interest: None

Funding Source: None

\section{Contribution}

All Authors have contributed in Study Design, Data Collection, Data Analysis, Data Interpretation, Manuscript Writing and Approval.
It was interpreted that she had insecure, disturbed childhood and had lots of stressors in her life which caused severe maladjustment, interpersonal conflict, feeling of rejection and loneliness. According to DSM5 she was diagnosed with Functional Neurological Symptom Disorder with comorbid Depressive Symptoms. The intervention plan comprised of psychodynamic, behavioral and cognitive approaches; techniques include catharsis, free association, anxiety reduction techniques, cognitive restructuring, graded task, mastery and pleasure technique, family psycho-education along with physiotherapy and physical exercise. Thirteen (13) therapeutic sessions were conducted along with anti-depressants and the patient showed marked improvement in all areas of her daily life. Family was psycho-educated to bring her for follow-up sessions.

Key words: Functional Neurological Symptom Disorder, psycho-social factors, maladjustment, interpersonal conflict.

\section{Introduction}

According to DSM-5, Functional Neurological Symptom Disorder (Conversion Disorder) is diagnosed when there is one or morevoluntary motor or sensory functions are altered. There is evidence by clinical findings, which show incompatibility between the presented symptoms and neurological or any medical condition. The symptoms cause significant impairment in the daily life functioning to be diagnosed as Functional Neurological Symptom Disorder. ${ }^{1}$

According to psychodynamic approach childhood traumatic experiences show devastating behavioural impacts on the entire life of the individual. Psychological dilemma is caused for children who face sepa- 
ration from parents and influence of surrogate parents, especially loss of mother during developing years predicts negative effect and depression. ${ }^{2}$ Researches provide evidence that symptoms of Functional Neurological Disorder usually develop in adolescence or early adulthood, typically after a major life stressor. According to the cognitive view, hysterical symptoms are a mode of communication. This is way of expressing emotions that would be difficult to express verbally as it might be considered inappropriate. Therefore, conversion symptoms are not a defense against anxiety instead they are ways of communicating intense feelings such as anger, fear, depression, jealousy, guilt, etc. ${ }^{3}$ Individuals who experience adverse childhood like loss or absences of parent figure develop negative schemas and when they face stressful life event such negative schemas reactivate. ${ }^{4}$ Previous researches revealed the significant relationship of childhood adversities like childhood abuse, neglect with high vulnerability of developing depression and the strong relationship between such childhood adversities and development of lifelong chronic depression. ${ }^{5-6}$ Twin studies also support the relationship between childhood traumatic experiences and the development of major depression. ${ }^{7,8}$

\section{Case Report}

F.Z 18 years old unmarried young girl, last born among 6 siblings; 4 sisters and 2 brothers, was brought to the psychiatry department. She presented with the speech symptom as she was unable to speak (aphonia), sensory symptom as she could not see (psychogenic blindness) and more over since last few months she had paralysis of lower limbs. Apart from those symptoms she reported poor appetite, remained sad and tearful. She was referred through Neurology Department to the Psychiatry Out Patient Department and was admitted in the ward, all the organic possibilities were ruled out.

The developmental history of the patient's problem indicated that she was adopted by her paternal uncle at the age of one and half year because they were issueless and her biological parents were financially very humble. She was much pampered child of her foster parents. At the age of 12 years, patient's foster parents had their own male child who started to receive all the attention of her poster parents. The patient started to feel neglected and becamestubborn and aggressive,under such emotions once she tried to hit that 2 years old child.Her foster parents scolded her badly for that misbehavior and she developed symptoms in the form of jerky movements and unable to speak (psychogenic aphonia). She was sent to her biological parents where she was treated by different faith healers and eventually recovered.

After recovery patient went back to her foster parents and again tried to hit their son who was rescued by her foster mother (aunt, chuchi). Her poster parents were so annoyed that they forcefully sent her back to her biological parents. She became so muchdisturbed at that time and lost her voice (aphonia). She was again treated by different faith healers and one of them sent her back to her foster parent's home. She remained symptom free for few months because her foster father (uncle, chucha) paid more attention to her but gradually he again started to neglect the patient and permanently sent her back to her biological parents. Her foster father was financing her but in the end he was not permitted by his wife to spend more money.At that time, patient's condition got severe, she became unable to speak (aphonia) and see (psychogenic blindness). After some days she had problem in walking and eventually she had paralysis of lower limbs. Apart from those symptoms she reported poor appetite, started to remain sad and tearful. Due to patient's severe condition her parents took her to the hospital where she was referred through Neurology Department to the Psychiatry Out Patient Department after ruling out all the organic possibilities.

After detailed history taking, she was psychologically assessed both informally and formally through Mental Status Examination (MSE), behavioral observation along with projective, semi projective tests which includes House Tree Person (HTP), Rotter's Incomplete Sentence Blank (RISB) and Beck Depression Inventory (BDI). She was prescribed antidepressant and her psychological management was based on psychodynamic, behavioral and cognitive approaches. Her management plan was developed on Biopsychosocial model. In the initial sessions rapport was tried to buildup. Initially she was tearful, reluctant and produced multiple sounds with head nodding as if it was not possible for her to speak. She was motivated by strong suggestion for a placebo shot and it was administered to her latter on. When she became able to speak, catharsis was done and she expressed the scars of adoption and multiple grievances against her biological and foster parents.After following the anxiety reduction techniques and progressive muscle relaxation exercises, she started moving her limbs. Around $5^{\text {th }} 6^{\text {th }}$ ses- 
sion she was able to walk with support and talk with difficulty but vision was still blurred. Daily activity schedule was assigned along with extinction in which previously reinforced behavior was not reinforced. Family was psycho educated to reinforce the desired behavior like doing daily chose and finally differential reinforcement was applied in which maladapted behavior was extinct and desirable was reinforced. In last sessions her cognitive distortions were identified and restructuring was done. She was symptom free by the end of almost $13^{\text {th }}$ session. Family was psycho educated for follow up sessions.

\section{Discussion}

In the present case, factors associated with good prognosis are: good family support, acceptance of the diagnosis and compliance towards treatment. Maladaptive personality traits of the client like oversensitivity, stubbornness and anger towards others are contributing factors for poor prognosis. ${ }^{9}$ As the client was in adolescent period, the prognosis of conversion disorder is reported to be better in younger children as compared to adolescents and adults.

Previous literature showed that maladaptive personality traits are commonly associated with conversion disorder. There may be a history of childhood abuse and neglect. Stressful life events are also the contributing factor, but are not always. Stress either psychological or physical may lead towards the onset. The potential etiological relevance of this stress or trauma may be suggested by a close temporal relationship. Females are two to three times more prone to conversion disorder as compared to males.Conversion disorder has high co-morbidity with depressive disorders. ${ }^{1}$ All these findings are consistent with the above mentioned case.

\section{Conclusion}

Adopted children had multiple scars and had no roots; they feel so insecure and become shuttle cock which really damages their upbringing. Psychosocial life stre- ssors are important causal factors and also precipitate conversion reaction in predisposed children. Emotional, psychological stressors profoundly affect not only the physical and psychological health of children but also later on their whole life. So, the timely identification of these stressors is very important for management of conversion disorder.10

\section{References}

1. American Psychiatric Association. Diagnostic and statistical manual of mental disorders ( $5^{\text {th }}$ ed.: DSM-5.). Washington DC: Authors, 2013.

2. Kivela SL, Kongas SP, Laippala P, Pahkala K, Kesti E. Social and psychosocial factors predicting depress-ion in old age: A longitudinal study. International Psychogeriatrics, 1996; 8: 635-644.

3. Davison G, Neale J. Abnormal psychology. USA: John Wiley \& Sons, 2012.

4. Beck AT. Cognitive models of depression. Journal of Cognitive Psychotherapy, 1987; 1: 5-37.

5. Chapman DP, Whitfield CL, Felitti VJ, Dube SR, Edwards VJ \& Anda RF. Adverse childhood experiences and the risk of depressive disorders in adulthood. Journal of Affective Disorders, 2004; 82: 217-225.

6. Edwards VJ, Holden GW, Felitti VJ, Anda RF. Relationship between multiple forms of childhood maltreatment and adult mental health in community respondents: Results from the adverse childhood experiences study. American Journal of Psychiatry, 2003; 160: 1453-1460.

7. Kendler KS, Kessler RC, Neale MC, Heath AC, Eaves L. The prediction of major depression in women: Toward integrated etiologic model. American Journal of Psychiatry, 1993; 150: 1139-1148.

8. Nelson EC, Heath AC, Madden PA, Cooper M, Dinwiddie SH, Bucholz KK, et al. Association between self-reported childhood sexual abuse and adverse psychosocial outcomes: Results from a twin study. Archives of General Psychiatry, 2002; 59: 139-145.

9. Hashmi AM, Mazhar N \& Malik AK. The burden on her soul: Conversion disorder in developing countries. ANNALS, 2012: 9-11.

10. Niaz Maqsood N, Akram B, Luqman N, Amin R. Conversion disorder; Psycho-social stressors and life events in children. The Professional Medical Journal, 2014; 21 (3): 489-494. 